\title{
Pesan Dakwah Akhlak Dalam Animasi Serial Nusa Dan Rara Pada Episode Toleransi Di Media Youtube; Analisa Simiotik Roland Barthes
}

\author{
Deva Ristianto ${ }^{1}$, Amalia Rosyadi Putri ${ }^{2}$, Tenika Illananingtyas ${ }^{3}$ \\ 123 Institut Agama Islam Tribakti Kediri \\ 1.Devaristianto768@gmail.com, 22 amaliarosyadi16@gmail.com 3tenikaillananingtyas07@gmail.com
}

\begin{abstract}
Nussa animation is an animation which is categorized as a medium for preaching. Because the messages conveyed were thick with Islamic teachings. However, not all viewers can understand what messages are contained in the animation. Due to this reason, the study aims to determine the messages of moral da'wah that can be seen directly or indirectly with Ronald Barthes' semiotic theory. The method used in this research is qualitative analysis, with data in the form of documents. Data collection using observation and documentation. The theory that is used as the basis is Roland Barthes' semiotic theory which focuses on denotative and connotative meanings. The results of the study are the denotative meaning of dakwah morals, (1) Have an attitude of help. (2) Always say thank you for a help. (3) Always have a sincere nature when helping. (4) Doing rejection well. (5) Providing opportunities for children to do good (6) giving love to children. (7) always say "Astafirullah" when hit / hear a disaster and say "Alhamdulillah as a form of gratitude. Meanwhile, the meaning of the message of moral teaching is connotative, (1) It shows that Islam is a soft religion, rahmatan lil alamin, helpful and tolerant (2) Want to break the paradigm under the religion of Islam having followers who are very rigid and do not want to interact with other people. (3) Providing education to children to do good deeds with anyone regardless of status and religion. Keywords: Moral Da'wah Messages, Animated Serial Nussa Episode Tolerance, Ronald Barthes' Semiotic Theory.
\end{abstract}

\begin{abstract}
Abstrak
Animasi Nussa merupakan sebuah animasi yang dikategorikan sebagai media untuk berdakwah. Karena pesan-pesan yang disampaikan kental dengan ajaran-ajaran Islam. Namun tidak semua penonton dapat memahami pesan apa saja yang terdapat dalam animasi tersebut. Dikarenakan alasan ini penelitian bertujuan untuk mengetahui pesanpesan dakwah akhlak yang dapat dilihat secara langsung maupun tidak langsung dengan teori semiotik Ronald Barthes. Metode yang digunakan pada penelitian ini adalah kualitatif analisis, dengan data-data yang berupa dokumen. Pengumpulan data menggunakan observasi dan dokumentasi. Teori yang dijadikan landasan adalah teori semiotik Roland Barthes yang berfokus pada pemaknaan secara denotatif maupun konotatif. Hasil penelitian yaitu makna pesan dakwah akhlak secara denotatif, (1)Memiliki sikap tolong menolong.(2)Selalu mengucapkan terimakasih atas sebuah bantuan.(3)Selalu memiliki sifat ikhlas ketika membantu. (4)Melakukan penolakan dengan baik.(5)Memberikan kesempatan anak untuk berbuat baik.(6) memberikan kasih sayang kepada anak. (7)selalu berkata "Astafirullah" ketika terkena/mendengar sebuah musibah dan berkata "Alhamdulillah sebagai bentuk rasa syukur. Sedangkan makna pesan dakwah akhlak secara konotatif, (1) Menunjukan bahwa agama Islam merupakan agama yang lembut, rahmatan lil alamin, suka menolong dan
\end{abstract}

Jurnal Kopis: Kajian Penelitian dan Pemikiran Komunikasi Penyiaran Islam

Volume 3, issue 01, Agustus tahun 2020 
toleransi. (2) Ingin mematahkan paradigma bawah agama Islam memiliki pemeluk yang sangat kaku dan tidak ingin berinteraksi dengan orang lain.(3)Memberikan pendidikan kepada anak-anak untuk melakukan perbuatan baik dengan siapapun tanpa melihat status dan agama.

Kata Kunci : Pesan Dakwah Akblak, Animasi Serial Nussa Episode Toleransi, Teori Semiotik Ronald Barthes.

\section{Pendahuluan}

Indonesia merupakan negara yang terdiri dari berbagai macam suku, bangsa, bahasa dan agama. Hal ini menjadikan Indonesia merupakan negara yang kaya akan kebudayaan. Kemajemukan bangsa Indonesia tidak hanya dilihat dari beragamnya jenis suku bangsa, namun juga agama yang dianut oleh penduduknya. Agama yang secara resmi diakui oleh pemerintah Indonesia adalah agama Islam, Katolik, Kristen, Hindu, Budha dan Kong hu chu. Hal ini menujukan bahwa perbedaaan agama yang dianut oleh masyarakat Indonesia.

Perbedaan tersebut jika tidak dipelihara dengan baik maka akan muncul konflik antar umat beragama yang bertentang dengan nilai-nilai dasar agama itu sendiri yang mengajarkan sebuah kedamaian, saling menghormati dan saling tolong menolong. Sehingga untuk mencegah terjadinya sebuah konfilk munculah sikap toleransi antar umat beragama.

Pada era globalisasi ini membuat masyarakat dengan mudah menerima sebuah informasi melalui media sosial, hal ini juga merupakan tantangan baru untuk tetap memiliki sikap toleransi. Karena saat ini masyarakat Indonesia sudah mulai bermunculan sikap intoleransi antar umat beragama, contohnya berita yang berjudul Begitu juga dengan berita yang berjudul "Salib dipotong hingga Tolak Sedekah Laut, 4 Kasus Intoleransi di Yogyakarta". Menjelaskan bentuk sikap intoleransi yang terjadi di wilayah Yogyakarta. ${ }^{1} \mathrm{Hal}$ ini menujukan bahwa sikap intoleransi sudah tumbuh di masyarakat Indonesia.

Agama Islam secara positif mendukung kerungan hidup beragama. Sikap kerukunan hidup beragama sudah tertanam dalam setiap pribadi muslim berdasarkan Al-Quran yaitu surah Hujurat 49/13:

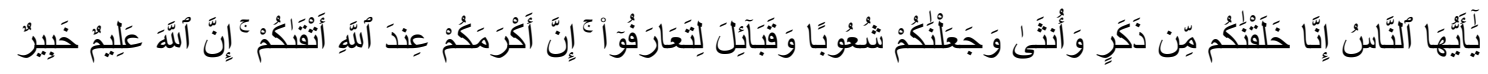

Artinya :

"Hai manusia, Sesungguhnya Kami menciptakan kamu dari seorang laki-laki dan seorang perempuan dan menjadikan kamu berbangsa - bangsa dan bersuku-suku supaya kamu saling kenal-mengenal.Sesungguhnya orang yang paling mulia diantara kamu disisi Allah ialah orang yang paling taqwa diantara kamu.Sesungguhnya Allah Maha mengetahui lagi Maha Mengenal"

Ayat tersebut mengandung makna perdamaian diantara satu sama lain, baik dalam ruang lingkup kecil maupun besar. Jadi perluh disadari sebagai umat beragama harus menjaga sikap antar sesama, karena itu sudah menjadi bagian dari falsafah pancasila yang saling mengutamakan kebebasan beragama. Menjaga sikap dalam

\footnotetext{
${ }^{1}$ Rendy Adrikni Sadikin.”Salip Dipotong Hingga Tolak Sedekah Laut, 4 Kasus Intoleransi di Yogyakarta”. Suara.com, https://www.suara.com/news/2019/04/03/163344/salib-dipotong-hingga-tolak-sedekah-laut-4-kasus-intoleransi-di-yogyakarta, 03 April 2019
} 
menciptakan kerukunan umat beragama sebagai faktor persatu stabilitas dan kemajuan bangsa. ${ }^{2}$

Pada era globalisasi ini banyak sekali metode dakwah dengan menampilkan kajian-kajian islami di media sosial seperti facebook, Instagram, Twitter, Youtobe dan lainnya untuk menampilkan konten-konten yang memiliki nilai-nilai islami.

Kecanggihan internet mulai dimanfaatkan umat Islam untuk berbagi keperluhan. Mulai dari keperluhan pribadi sampai keperluhan dakwah. Situs-situs Islam bermunculan dengan berbagai model yang ditampilkan. Oleh karena itu, umat Islam diwajibkan untuk berdakwah, walapun hanya sedikit, tapi kita wajib mendakwahkanya kepada orang lain. Dakwah tentunya bisa dengan berbagai cara salah satunya memanfaatkan media Internet. ${ }^{3}$

Internet merupakan bentuk kemajuan teknologi dalam ilmu teknologi komunikasi yang merupakan saranan atau media yang dapat digunakan oleh seluruh golongan manusia. Begitu juga dengan para $d a^{\prime} i$ dalam proses berdakwahya, bisa memanfaatkan internet untuk menjadi media dakwah dalam menyembarkan nila-nilai Islami kepada masyarakat luas

Dakwah merupakan suatu proses Islamisasi nilai-nilai terhadap kehidupan manusia, sudah semestinya seorang da'i mampu untuk menyikapi dengan adanya perkembangan pengetahuan dan teknologi yang semakin modern. Hal ini mengharuskan seorang $d a^{\prime} i$ mampu untuk ikut serta memanfaatkan perkembangan ini agar dapat bersaing dalam menyampaikan nilai-nilai keagamaan kepada umat manusia.

Ada banyak cara berdakwah di media sosial, salah satunya melalui film animasi, film animasi merupakan gambaran yang dilukiskan dengan garis-garis yang sederhana dan bergerak seperti hidup. Animasi dijadikan saranan dakwah atau media komunikasi tentang Islam terhadap anak-anak, remaja maupun orang dewasa. Artinya animasi adalah menghidupkan gambar. ${ }^{4}$

Saat ini animasi sudah dikenal oleh banyak orang, bahkan di beberapa negara banyak yang menciptakan animasi yang bervariasi agar masyarakat senang dan tertarik dengan animasi yang telah diciptakan. Selain sebagai bahan untuk hiburan semata, animasi juga bisa dijadikan sebagai ladang pendapatan dan bahkan menyebarkan nilainilai seperti apa yang dimiliki oleh pemilik/pencipta animasi tersebut.

Pada November 2018 masyarakat Indonesia menemukan cahaya terang, yaitu mulai mengeluarkan gebrakan. Web serial animasi Nussa dan Rara yang telah merilis episode pertama di channel youtobe Nussa Official, menjadi napas baru bagi dunia animasi Indonesia. Dalam peluncuran yang pertama ini mendapatkan sambutan yang sangat baik oleh masyarakat Indonesia, episode perdana dari Nussa Official kini telah disaksikan 2,2 juta penonton dan memiliki 400 ribu lebih subscriber. Saat ini di tahun januari 2020 telah mencapai 5,08 juta subscriber dan sudah share 109 video di channel youtobenya. ${ }^{5}$

\footnotetext{
${ }^{2}$ Weinata, Sairin, Kerukunan Umat Beragama Pilar Utama Kerukunan Berbangsa (Jakarta: Gunung Mulia, 2002).h. 48

3 Anggraini Icke Lutfi, "Nilai-Nilai Islam Dalam Serial Animasi Nussa”. (Skripsi, Fakultas Dakwah dan Komunikasi. Program Studi Komunikasi dan Penyiaran Islam. Purwakarta: Institut Agama Islam Negeri (IAIN) Purwakarta,2019).

4 Hilman Agus,"Pengertian Animasi dan Sejarah Animasi" Academia, vol.1, 2011, hlm.6.

${ }^{5}$ Nurfina Fitri Melina."nussa dan rara gebrakan animasi Indonesia siapa sih dibelakanya", trimbunnews.com,https://www.tribunnews.com/seleb/2018/11/29/nussa-dan-rara-gebrakan-animasi-indonesia-siapa-sih-dibelakangnya, diakses pada 8 Januari 2020.
} 
Serial Animasi Nussa ini mengisahkan tentang keseharian seorang anak laki-laki yang bernama Nusa dan adiknya Rara yang berusia 5 tahun yang menggemaskan dan memberikan eduksi Islami untuk di tonton semua kalangan khusunya bagi anak-anak..

Karena Animasi Nussa ini kaya akan nilai-nilai Islami yang selalu digambarkan dalam setiap ceritanya. Salah satu nilai - nilai Islami yang terkandung di dalam serial ini adalah nila-nilai akhlak. Akhlak secara terminologi berarti tingkah laku seseorang yang didorong oleh suatu keinginan secara sadar untuk melakukan suatu perbuatan yang baik. Akhlak merupakan bentuk jamak dari kata khuluk, berasal dari bahasa Arab yang berarti perangai, tingkah laku, atau tabiat. Cara membedakan akhlak, moral, dan etika, yaitu dalam etika, untuk menentukan nilai perbuatan manusia baik atau buruk menggunakan tolok ukur akal pikiran atau rasio, sedangkan dalam moral dan susila menggunakan tolok ukur norma-norma yang tumbuh dan berkembang dan berlangsung dalam masyarakat (adat istiadat), dan dalam akhlaq menggunakan ukuran Al Qur'an dan $\mathrm{Al}$ Hadis untuk menentukan baik-buruknya. ${ }^{6}$

Karena nilai-nilai yang diangkat merupakan nilai yang baik dan berdasarkan pada Al-Quran \& hadist. Salah satu nilai yang patut untuk diatuskan dalam kehidupan sehari hari adalah nilai-nila toleransi, apalagi kita hidup di negara yang memiliki banyak sekali perbedaan. Oleh karena itu sikap toleransi sangatlah penting, namun masih banyak masyarakat Indonesia yang minim akan sikap toleransi seperti yang sudah dijelaskan diatas. Maka peneliti tertarik untuk melakukan penelitian tentang memahami makna pesan dakwah fokus di nilai Akhlak pada episode yang berjudul "Toleransi"di media youtobe. Sehingga dari latar belakang diatas peneliti ingin meneliti "Pesan Dakwah Akhlak Dalam Animasi Serial Nusa dan Rara Pada Episode Toleransi Di Media youtobe (Analisa Simiotik Roland Barthes)

\section{Metode Penelitian}

Sesuai dengan tema yang diangkat oleh peneliti yaitu ingin menganalisa makna pesan dakwah akhlak apa yang terdapat dalam serial Nussa pada episode "Toleransi" di media youtobe. Maka dalam penelitian ini peneliti menggunakan pendekatan kualitatif jenis analisis. Sehingga yang menjadi fokus perhatian adalah makna pesan dakwah akhlak apa yang terdapat pada serial Nussa episode "Toleransi" di media youtobe berdasarkan analisa teori semiotik Ronald Barthes.Alasan peneliti menggunakan pendekatan kualitatif karena data yang akan digunakan dalam penelitian ini merupakan data kualitatif (data yang tidak berupa angka-angka).

Analisa semiotik Ronald Brathes adalah memahami makna-makna secara langsung, tidak langsung dan mitos. Namun dalam mengungkapkan makna-makna pesan dakwah akhlak apa yang terdapat pada serial Nussa episode "Toleransi" di media youtobe hanya fokus pada makna secara langsung (denotasi) dan tidak langsung (konotasi).

Sumber data dalam penelitian ini umumnya terdapat dua jenis, yaitu sumber data primer dan data sekunder. ${ }^{8}$

a. Sumber Primer, sumber data yang akan menjadi rujukan utama ini adalah animasi serial Nussa dan Rara episode yang berjudul "Toleransi” di media youtobe dengan mengamati tentang pesan dakwah akhlak yang terkandung di dalamnya.

\footnotetext{
${ }^{6}$ Wikipedia Eksikopedia bebas.”Akhlak" https://id.wikipedia.org/wiki/Akhlak, diaksed pada 17 Januari 2020.

${ }^{7}$ Lexy J Moleong, Metodologi Penelitian Kualitatif (Bandung: PT, Remaja Rosda Karya, 2005), h. 6.

${ }^{8}$ Sugiyono, Metode Penelitian Pendidikan Pendekatan Kuantitatif, Kualitatif, dan Re D, Cet. VI (Bandung: Alfabeta, 2008), h. 110.
} 
b. Sumber Sekunder, data yang dikumpulkan oleh orang atau lembaga lain untuk melengkapi sumber primer seperti artikel dan website yang terkait dengan film animasi serial Nussa dan Rara episode yang berjudul "Toleransi".

Dalam penelitian, peneliti mengunakan teori Ronald Barthes untuk menganalisa makna pesan yang terkandung dalam animasi tersebut secara konotatif dan denotatif. Untuk tahapanya dalam penelitian tergambarkan oleh bagan di bawah ini menggunakan teori semiotik Ronald Barthes digambarkan sebagai berikut:

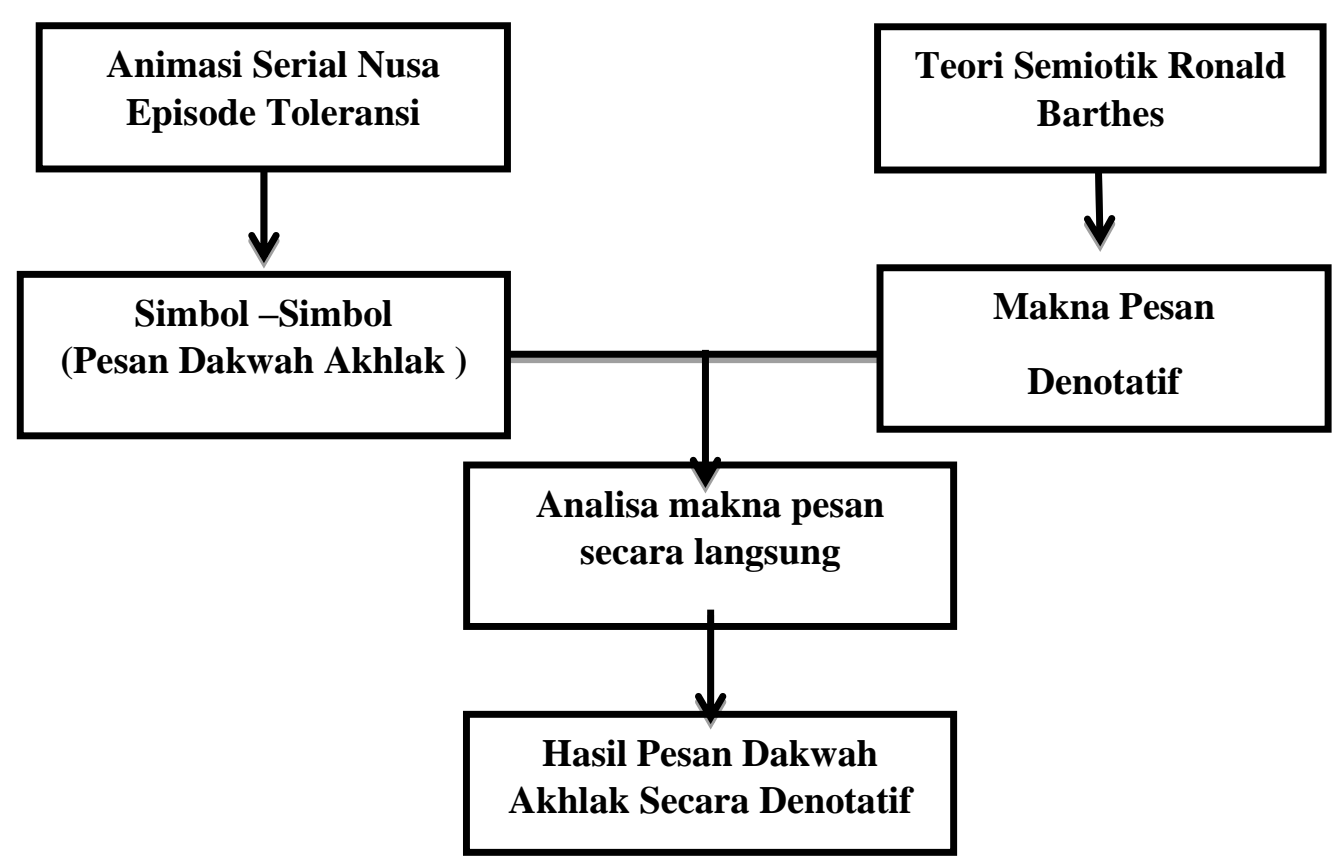




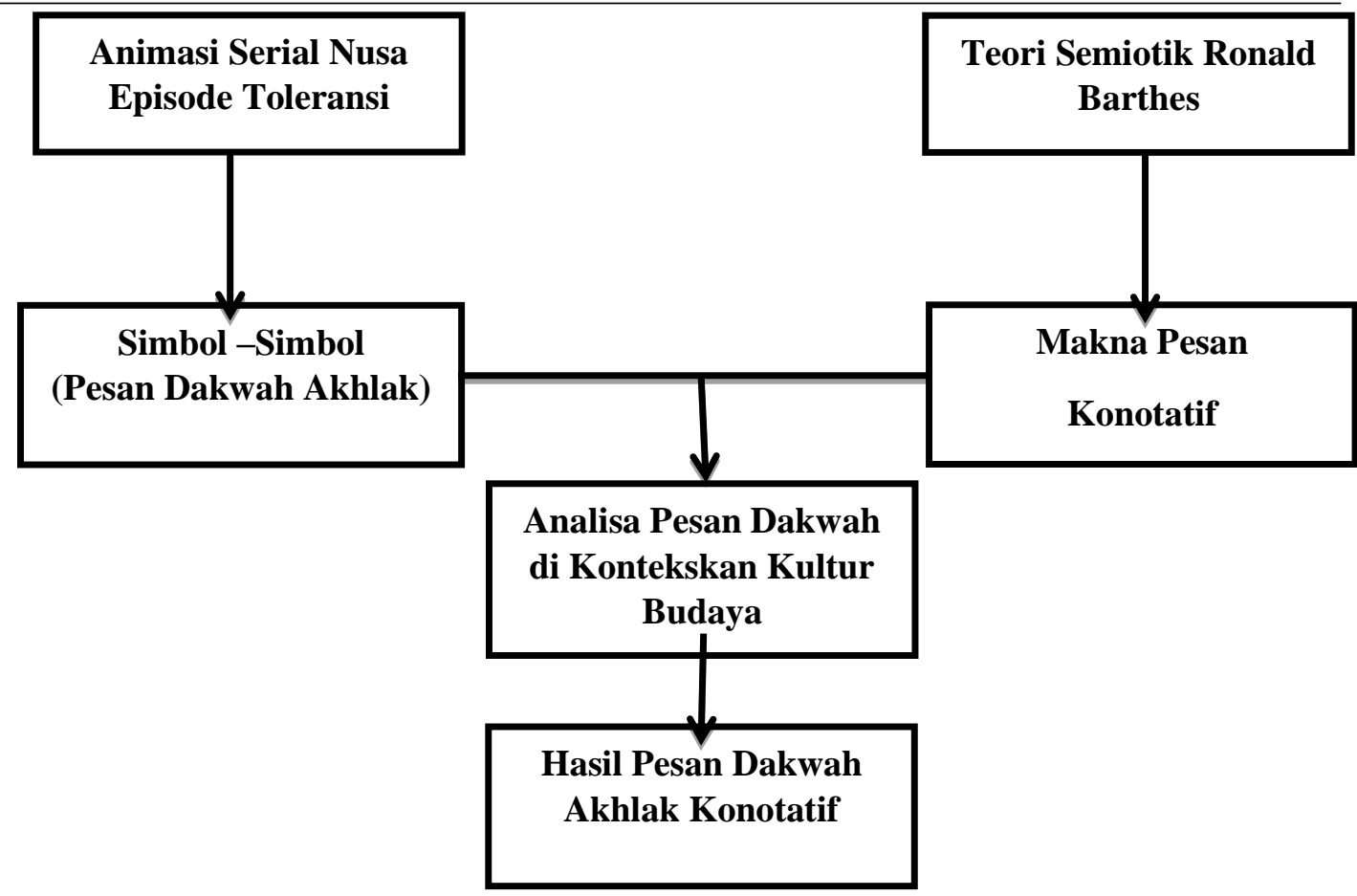

Tabel 2.3. Kerangka Berfikir

\section{Hasil dan Pembahasan}

1. Hasil Temuan Makna Pesan Akhlak Dakwah Animasi Serial Nussa : Episode Tolerasi.

Dalam hasil temuan ini peneliti akan membagi kedalam beberapa sub yaitu menemukan makna denotatif kemudia dilanjutkan dengan makna konotatif dan disimpulkan temuan makna pesan dakwah akhlak sesuai dengan penalaran makna konotatif.

\section{a. Temuan Makna Denotatif Animasi Serial Nussa Episode Toleransi}

Tahapan dalam melakukan analisis semiotik Roland Barthes adalah dengan menghubungkan antara penada (signifier) dan petanda (signified) untuk menemukan makna denotasi yang ditampilkan. Makna denotasi merupakan makna secara langsung, pasti dan makna sebenarnya. Berikut ini peneliti mendeskripsikan bentuk denotasi dalam serial Nussa episode Toleransi.

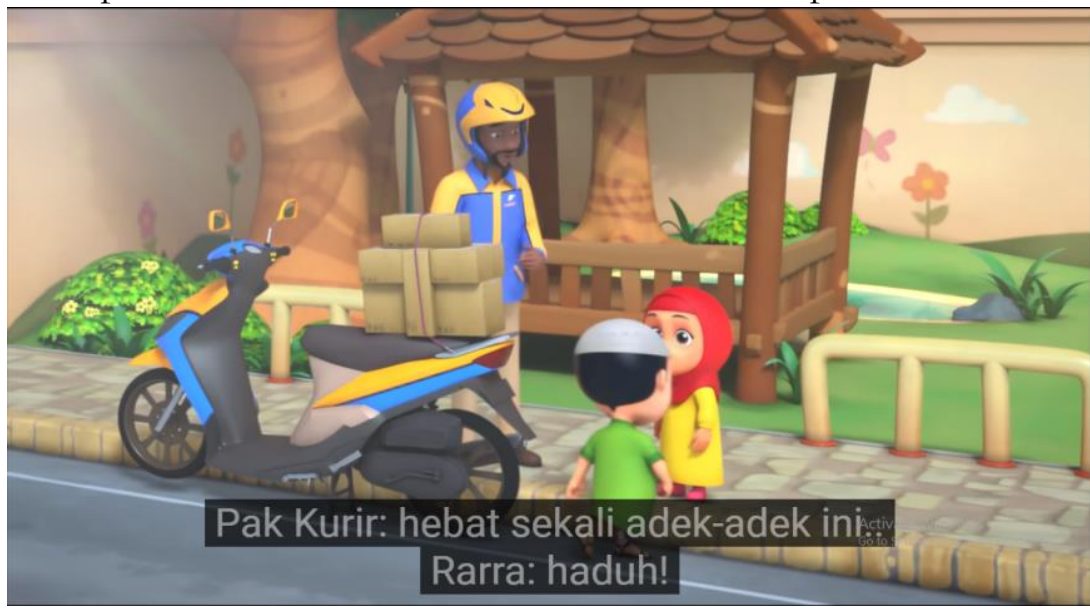

\section{Gambar Scene Pertama}

Pada Scene pertama ini menujukan bahwa Nussa dan Rara sedang bermain di taman kemudian melihat pak kurir yang sedang kesusahkan menata barang di 
motornya. Hal ini membuat Nussa dan Rara segera mungkin untuk membantu pak kurir untuk menata barang-barang di atas motornya. Ketika membantu terdapat percakapan yang terlontarkan diantara mereka misalnya kata "Terimakasih" dari pak kurir dan "Nussa dan Rara Bantuin ya kak" dari suara Nussa dan Rara.

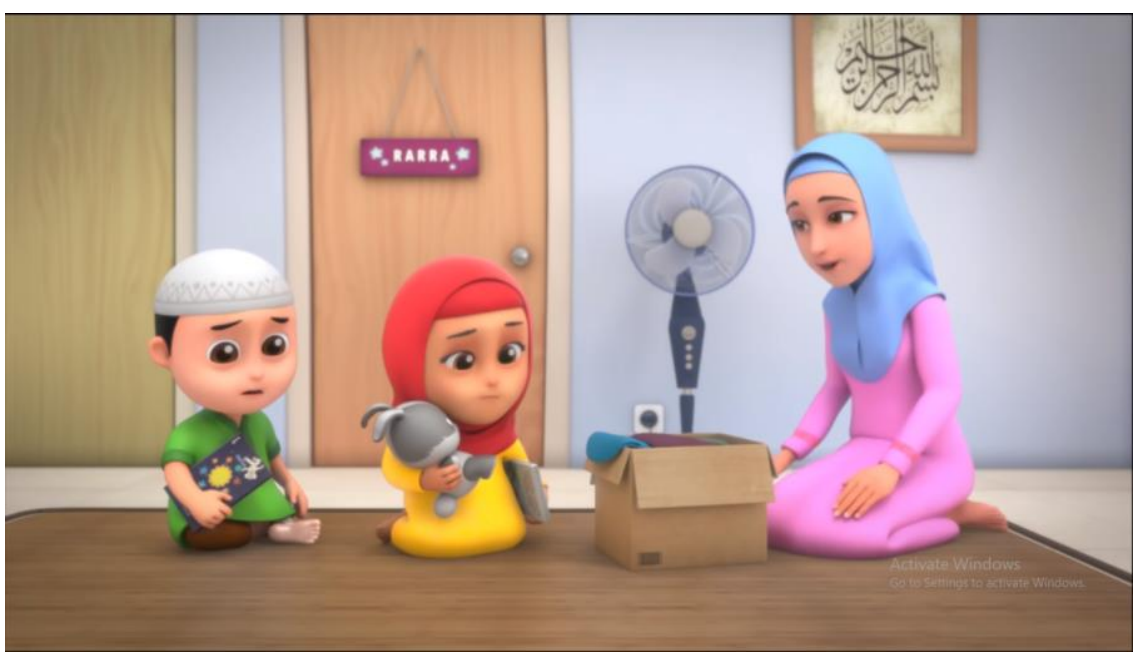

Gambar Scene dua

Pada Scene ke dua dimulai dengan Umma yang di telpon oleh temannya yang sedang kena musibah kebakaran. Dalam cerita ini teman Umma memiliki agama . Non Muslim. Melihat Umma setelah ditelpon menujukan raut muka yang sedih dan menyiapkan beberapa barang, maka Nussa dan Rara kebingungan dan mulai bertanya. Kemudian di jelaskan Umma bahwa teman Umma sedang mengalami musibah, mendengar hal itu Nussa dan Rara mencoba membantu sebisa mereka dengan memberikan buku dan tas

Sehingga dari gerakan tubuh, percakapan dan suasana yang mana jika dianalisa menggunakan pendekatan semiotik Ronald Barthes secara denotatif maka dapat diambil kesimpulan bahwa makna pesan dakwah akhlak yang terkandung didalamnya ada beberapa hal yaitu :

a. Ketika saudara/teman kita terkena musibah maka sudah seharunya kita ikut membantu dengan memberikan sedikit apa yang kita punya (tolong menolong sesama manusia).

b. Memberikan kesempatan kepada anak-anak kita untuk ikut serta membantu dengan apa yang mereka miliki. Sebagai bentuk penghargaan dan pembelajaran sejak dini.

c. Ketika ingin membantu, membantulah dengan Ikhlas tanpa mengharapkan sesuatu.

d. Selalu memberikan kasih saya kepada anak-anak kita. Karena dengan kasih saya merupakan salah satu bentuk perhatian orang tua kepada anaknya. 
e. Selalu berkata "Astafirullah" ketika musibah/menderang sebuah musibah dan berkata "Alhamdulillah" sebagai bentuk rasa syukur.

\section{b. Temuan Makna Konotatif Animasi Serial Nussa Episode Toleransi}

Makna konotatif/konotasi merupakan tanda dan penandanya mempunyai keterbukaan makna/makna yang implisit, tidak langsung dan tidak pasti. Artinya memiliki banyak kemungkinan hasil tafsir yang baru. Dalam kerangka Barthes, konotasi dihubungkan dengan kultur/realitas yang ada di masyarakat baik dari segi budaya dan adat istiadat. Sehingga makna konotasi dapat diambil dari simbolsimbol dan dihubungkan dengan kultur/budaya masyarakat yang ada, misalkan kata "Kursi" secara umum atau secara denotasi memiliki makna tempat duduk, namun secara makna konotasi akan menghasilkan makna sebuah jabatan/kedudukan.

Makna konotasi dalam serial Nussa pada episode "Tolerasi" ingin menujukan bahwa Islam merupakan agama yang lembut, rahmatan lil alamin, suka menolong dan sangat toleransi. Hal ini juga ingin mematahkan paradigma bahwa Islam memiliki pemeluk yang sangat kaku dan tidak ingin berinteraksi dengan agama lain selain Islam. Selain itu juga ingin memberikan gambaran/pendidikan kepada anak-anak untuk melakukan perbuatan dengan siapapun tanpa melihat status dan agamanya.

Dari pernyataan diatas terbentuk karena beberapa hal yang ditemukan peneliti dari hasil pengamatan dengan melihat dan mendengar apa saja yang terjadi dianimasi serial Nussa episode "Toleransi". hal inilah beberapa faktor yang menguatkan hasil kesimpulan peneliti, yaitu: (1) Dalam scene pertama menujukan dimana Nussa dan Rara membantu Pak Kurir yang memiliki agama yang berbeda dan di scene ke dua keluarga Nussa membantu teman Umma yang memiliki agama yang berbeda (2) Banyak sekali adegan yang menujukan bahwa Islam merupakan agama yang tolong menolong dan toleransi yang mana menujukan bahwa Islam agama yang rahmatan lil alamin,

\section{Kesimpulan}

Berdasarkan pembahasan yang telah diuraikan dengan menggunakan model analiasa Roland Barthes, peneliti menemukan adanya makna pesan akhlak yang terdapat dalam serial Nussa episode "Toleransi" di media youtobe. Berikut ini kesimpulan yang peneliti dapatkan:

1. Makna pesan dakwah akhlak dalam animasi serial Nussa dan Rara pada judul "Toleransi" secara denotatif berdasarkan analisa semiotik Roland Barthes yaitu menujukan sikap tolong menolong tanpa melihat suku, tidak pamrih dan berkata baik.

Hal ini merupakan bentuk pesan dakwah akhlak yang bisa kita lihat secara langsung di serial Nussa episode "Tolerasi” dengan mengamati/mendengarkan simbol-simbol yang dimunculkan dan kita maknai secara langsung.

2. Makna pesan dakwah akhlak dalam animasi serial Nussa dan Rara pada judul "Toleransi" secara konotatif berdasarkan analisa semiotik Ronald Barthes, yaitu 
menujukan bahwa Islam merupakan agama rahmatan lil alamin, suka membantu dan memberikan pendidikan kepada anak dengan memberikan contoh yang baik

Hal ini merupakan bentuk pesan dakwah akhlak dalam serial Nussa episode "Toleransi" dalam sudut pandang makna konotatif. Dimana makna bisa disimpulkan karena adanya simbol yang di hubungan dengan kultur, adat istiadat dan konteks keluarnya simbol tersebut. Sehingga dari analisa peneliti yang sudah menghubungkan simbol dengan kultur, adat istiadat dan konteks, menyimpulkan terdapat tiga poin tersebut.

\section{DAFTAR PUSTAKA}

Adrikni Sadikin Rendy."Salip Dipotong Hingga Tolak Sedekah Laut, 4 Kasus Intoleransi di Yogyakarta". Suara.com,https://www.suara.com/news/2019/04/03/163344/salibdipotong-hingga-tolak-sedekah-laut-4-kasus-intoleransi-di-yogyakarta

Hilman Agus,"Pengertian Animasi dan Sejarah Animasi” Academia, vol.1, 2011

Icke Lutfi Anggraini, "Nilai-Nilai Islam Dalam Serial Animasi Nussa". (Skripsi, Fakultas Dakwah dan Komunikasi. Program Studi Komunikasi dan Penyiaran Islam. Purwakarta: Institut Agama Islam Negeri (IAIN) Purwakarta,2019).

Lexy J Moleong, Metodologi Penelitian Kualitatif (Bandung: PT, Remaja Rosda Karya, 2005) Muslim,Hadits Arba'in An Nawawi hadits ke 36

Nurfina Fitri Melina."nussa dan rara gebrakan animasi Indonesia siapa sih dibelakanya", trimbunnews.com,https://www.tribunnews.com/seleb/2018/11/29/nussa-dan-raragebrakan-animasi-indonesia-siapa-sih-di-belakangnya

QS. Yunus Ayat 40-41, kementrian Agama Republik Indonesia Al-Qur'an dan Terjemahan (Jawa Tengah : Sahabat, 2013).

Sairin, Weinata, Kerukunan Umat Beragama Pilar Utama Kerukunan Berbangsa (Jakarta: Gunung Mulia, 2002).

Sugiyono, Metode Penelitian Pendidikan Pendekatan Kuantitatif, Kualitatif, dan R\&D, Cet. VI (Bandung: Alfabeta, 2008)

Wikipedia Eksikopedia bebas."Akhlak" https://id.wikipedia.org/wiki/Akhlak 